\title{
Mapping of PM10 surface concentrations derived from satellite observations of aerosol optical thickness over South-Eastern France
}

\author{
J.-C. Péré ${ }^{\mathrm{a}, \mathrm{b}, *}$, V. Pont ${ }^{\mathrm{b}}$, M. Mallet ${ }^{\mathrm{b}}$, B. Bessagnet ${ }^{\mathrm{a}}$ \\ a Institut National de l'Environnement Industriel et des Risques, INERIS, Parc Technologique ALATA-B.P. No. 2, 60550 Verneuil en Halatte, France

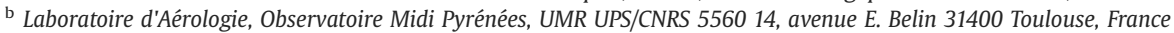

This work aims at developing a methodology based on in-situ experimental observations in order to use satellite retrievals as a tool for monitoring air particulate pollution. This methodology is applied during summer time on the South-Eastern France, which is one of the most polluted zones over Europe, enclosing further large cities and industrial sites. In a first time, we consider correlations between daily mean AERONET AOT and PM10 concentrations at five sites located as well close to as far from pollution sources. Our results show significant correlation coefficients, ranging from 0.68 to 0.79 , following the site studied. Several factors like aerosol vertical distribution or hygroscopic growth factor could affect the link between PM10 ground measurements and aerosol optical thickness. To statistically strengthen this approach, we gather data sets from three types of sites (urban, near urban and rural) and establish a linear relationship between daily mean AOT measured from AERONET and PM10 mass concentrations. Secondly and thanks to good agreements between AOT measured from AERONET and AOT retrieved from the MODIS sensor, we calculate estimated concentrations of PM10 by using MODIS retrievals above the South-Eastern France. Uncertainties about this approach are discussed.

\section{Contents}

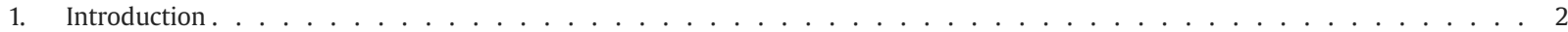

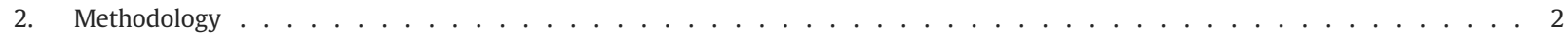

2.1. Description of observational sites . . . . . . . . . . . . . . . . . . . . . . . . . 2

2.2. PM10 measurements . . . . . . . . . . . . . . . . . . . . . . . . . . . . . . 3

2.3. Aerosol optical thickness measurements . . . . . . . . . . . . . . . . . . . . . . . . . . . 3

3. Results and discussion . . . . . . . . . . . . . . . . . . . . . . . . . . . . . 4

3.1. Comparison between PM10 ground mass concentrations and AOT from PHOTONS Sun photometers . . . . . . . . . . 4

3.2. Mapping of PM10 surface concentrations by using the MODIS sensor . . . . . . . . . . . . . . . . . . . . 5

3.2.1. Empirical relationship development . . . . . . . . . . . . . . . . . . . . . . . . . . 5

3.2.2. Application of the linear model to MODIS AOT retrievals . . . . . . . . . . . . . . . . . . 6

4. Conclusions and outlooks . . . . . . . . . . . . . . . . . . . . . . . . . . . . . . . . 7

Acknowledgements. . . . . . . . . . . . . . . . . . . . . . . . . . . 7

References . . . . . . . . . . . . . . . . . . . . . . . . . . .

* Corresponding author. Institut National de l'Environnement Industriel et des Risques, INERIS, Parc Technologique Alata-B.P. No. 2, 60550 Verneuil en Halatte, France. Tel.: + 330344558157.

E-mail address: Jean-Christophe.PERE@ineris.fr (J.-C. Péré). 


\section{Introduction}

At global scale, aerosol particles are known to play an important role on climate change. They directly affect the earth-atmosphere system radiative balance by scattering and absorbing solar and telluric radiation (Anderson et al., 2003), and indirectly by acting as additional cloud condensation nuclei. Higher aerosol concentration increases the initial cloud droplet number concentration, enhancing the cloud albedo (Twomey, 1974), and also enhancing cloud lifetime and liquid water content by lowering the precipitation efficiency of the cloud (Albrecht, 1989). However, quantifying these indirect effects remains a difficult task, as highlighted by IPCC (2007) assessment. An accurate quantification of these effects relies on a better characterization of the optical and physical properties of tropospheric aerosols and their temporal and spatial distributions (Kaufman et al., 2002). Ground based measurements, satellite observations and aerosol dynamics models are needed to understand the variability of such properties (Vachon et al., 2004). Combining these measurements enables to link the different temporal and spatial scales involved.

At local scale, elevated concentrations of air pollution can affect the human health. French authorities estimate that a growing exposure to PM10 pollution (mass of Particulate Matter with an aerodynamic diameter less than $10 \mu \mathrm{m}$ ) can increase the number of death causing by cardio vascular or respiratory diseases, notably with weak persons (Agence Française de Sécurité Sanitaire Environnementale, December 2004). Each year, one hundred of deaths would be caused by air pollution in the south-eastern PACA (Provence Alpes Côte d'Azur) region (ORS PACA, 2004), which is one of the most polluted zones in Europe. This region is characterized by a densely urbanised littoral and by the presence of more and more numerous industrial areas. Fixed emissions mainly due to the industrial pole of Fos Berre (the biggest one in southern Europe) and pollution due to dense traffic irrigate the entire region. The presence of complex topography combining Mediterranean coast and presence of mountains (French Alps, Massif Central) enhances the stagnation of polluted air masses (Drobinski et al., 2006). In addition, persistence of very sunny weather causes a high occurrence of photochemical pollution events (Cros et al., 2003). Consequently, bursts of particulate matter pollution become more frequent.

Air quality monitoring devices are located close to major urban areas and in pollution sensitive sites (Fos Berre's industrial pole). They supply regular and reliable concentration levels of various pollutants $\left(\mathrm{SO}_{2}, \mathrm{NO}_{2}, \mathrm{O}_{3}\right.$ and PM2.5/ PM10) but leave areas distant from pollution sources without any information about air quality. These local measurements are not numerous enough to provide health alerts on large spatial scales because aerosol concentrations are highly variable in space. Since ground measurements of Particulate Matter (PM) are sparse, the potential for retrieving indirect estimates of ground pollution using aerosol optical thickness (AOT) has been demonstrated at local scale: over Hong Kong, China (Li et al., 2005), over Ispra, Italy (Chu et al., 2003) and regional scale: over the United States (Engel-Cox et al., 2004) and France (Kacenelenbogen et al., 2006).

AOT represents the extinction of incoming solar radiation by aerosols over the whole atmospheric column. This parameter mainly depends on aerosol concentration, and vertical profile of the aerosol extinction coefficient, which is a function of the aerosol size distribution, complex refractive index (depending on the aerosol chemical composition) and hygroscopic growth factor (depending on the hydrophilic and/or hydrophobic properties of particles). AOT is an aerosol optical property which is now well retrieved from numerous sensors such as Moderate Resolution Imaging Spectroradiometer (MODIS) (Engel-Cox et al., 2004; Chu et al., 2003), Polarisation and Directionality of Earth's Reflectances (POLDER) (Kacenelenbogen et al., 2006) or Multi angle Imaging Spectro-Radiometer (MISR) (Liu et al., 2005), and well measured from ground-based Sunphotometer in the frame of the AERONET (AErosol RObotic NETwork) network (Holben et al., 1998). Thus, taking advantage of the strong correlation between AOT and PM, the use of satellite AOTretrievals data for air quality monitoring at a regional scale has become a topical challenge. Recent studies have developed an explicit formulation of the relationship between satellite AOT retrievals and PM to evaluate air quality in the United States and Canada (Van Donkelaar et al., 2006) or in Delhi Metropolitan, India (Kumar et al., 2007).

As mentioned above, the major goal of this work is to present a methodology (Section 2) dedicated to provide PM10 surface concentration maps over the PACA region from MODIS imagery AOT data. To reach this objective, first (Section 3.1), we establish an empirical relationship between daily mean PM10 ground mass concentrations and AERONET aerosol optical thickness observed over five sites characterizing three different environments (urban, suburban and rural) over the PACA region (see http://www.provence-hibiscus-locations. com/paca/). In a second time (Section 3.2), we have applied this empirical law to obtain PM10 surface concentrations from MODIS AOT in order to evaluate PM10 concentrations over the PACA region.

\section{Methodology}

In this section, we describe each site (urban, suburban and rural) considered in this work and corresponding available data (PM10 an AOT).

\subsection{Description of observational sites}

First, it should be mentioned here that our study focused on the PACA region, which is the third most important pollutants emitting region in France. Marseilles, the second most populated city in France (after Paris) with 800000 inhabitants and the huge industrial pole of Fos Berre (the biggest one in southern Europe with 10000 ha area), are the main sources of particulate pollutants of the PACA region.

In addition, this region is characterized by very sunny weather. Indeed, six of the nine sunniest cities in France are located in PACA (Toulon, Marseille, Carpentras, Saint Auban, Nice and Embrun). Consequently, high pollutant emissions and persistence of anticyclonic conditions are responsible for important photochemical episodes especially during summer time (Cros et al., 2003).

The region surrounding Marseilles, including Vallon d'Ol, is strongly affected by plumes of pollutants coming from the Marseille/Berre sources. In this coastal region, land-sea breezes channelled by complex relief can transport pollutants 
over the entire region (Fig. 1). Over the west of the region, Avignon and its surroundings can be affected by polluted air masses during daytime when incoming sea breeze flows induce a south-easterly flux that blows pollutants from Marseille and Fos Berre (purple arrows). Again, Vinon sur Verdon, just located at the entrance of the Durance Valley, can also be affected by pollution when air masses coming from the industrial pole rush into the valley (orange and red arrows). To the east of the region, the small mountains relief parallel to the coastline (Sainte Baume, Sainte Victoire, Luberon, Ventoux) tends to channel air masses along the coast (yellow arrows). Consequently, pollutants can be spread over Toulon and Nice (yellow arrows). Moreover, around Nice, pollution advection phenomena can occur when a southeasterly breeze brings polluted air masses from the Mediterranean Sea or Italy to inland (green arrows).

Consequently, due to specific blowing systems, numerous sites of PACA region can be affected by high concentrated pollutants. Notably, Cachier et al. (2005) show that aerosol loadings are significant over the whole PACA region. This aerosol is composed of different chemical species depending on the origin of sources. It mainly contains sulphates, nitrates, ammonium, black and organic carbon and minerals dust (Cachier, 1998; Mallet et al., 2003; Cachier et al., 2005). To survey the aerosol concentration levels over this region, PM10 and aerosol optical thickness measurement networks provide data. To capture high loadings of chemically aged aerosol, our study is focused on summertime period.

\subsection{PM10 measurements}

Particle mass concentration measured at the ground (in $\mu \mathrm{g} / \mathrm{m}^{3}$ ) is used as an indicator to evaluate air quality. In this study, we focus on particulate pollution for three types of built-up areas.

In urban zone (Marseille, Avignon, and Toulon), we use PM10 mass data measured at the ground by air quality agencies handled by ADEME (Agence de Developpement et de la Maîtrise de l'Energie). In suburban (Vallon d'Ol) and rural
(Vinon sur Verdon) areas we use PM10 data collected during the ESCOMPTE experiment (Cros et al., 2003). This campaign took place in the south east of France during June and July 2001. Its major goal was to create a very detailed database in order to develop and validate models by studying photochemical pollution (Cros et al., 2003).

Whichever sites considered, the PM10 mass concentration is determined every 15 min using a Tapered Element Oscillating Microbalance (TEOM) with an uncertainty of $\pm 10 \%$. An underestimation can exist on PM10 values due to the volatilization of ammonium nitrate or semi-volatile organic species during the conditioning procedure at $50{ }^{\circ} \mathrm{C}$ (Allen et al., 1997; Bessagnet et al., 2005). However, ammonium nitrate is weakly produced in summertime, only organic compounds could evaporate in the TEOM (Hodzic et al., 2005). Hence, we only use raw PM10 data with no correction factor. To compare them with daily mean aerosol optical thickness on the same time base, 1/4 hPM10 data are averaged to obtain daily PM10 mass concentration. Table 1 gives information about data availability for each site.

\subsection{Aerosol optical thickness measurements}

The AERONET (AErosol RObotic NETwork) network was established to gather Sun photometer measurements and to provide information to better quantify aerosol impact on climate forcing. This network consists in about 200 instruments spread over all continents (see AERONET website: http://aeronet.gsfc.nasa.gov/). The French part of AERONET is called PHOTONS (PHOtométrie pour le Traitement Opérationnel de Normalisation Satellitaire) and is administrated by the LOA (Goloub, 2004). Details of the concept and description of the remote sensing aerosol monitoring AERONET network are available in Holben et al. (1998). In this study, we use daily mean AOT level 2.0 data (cloud free and manually checked) (Smirnov et al., 2000) at $440 \mathrm{~nm}$ measured at the five sites collocated with PM10 ground-based measurements. The uncertainty on AOT measurements is \pm 0.01 (Holben et al., 1998). Only AOT corresponding to high Angstrom coefficients

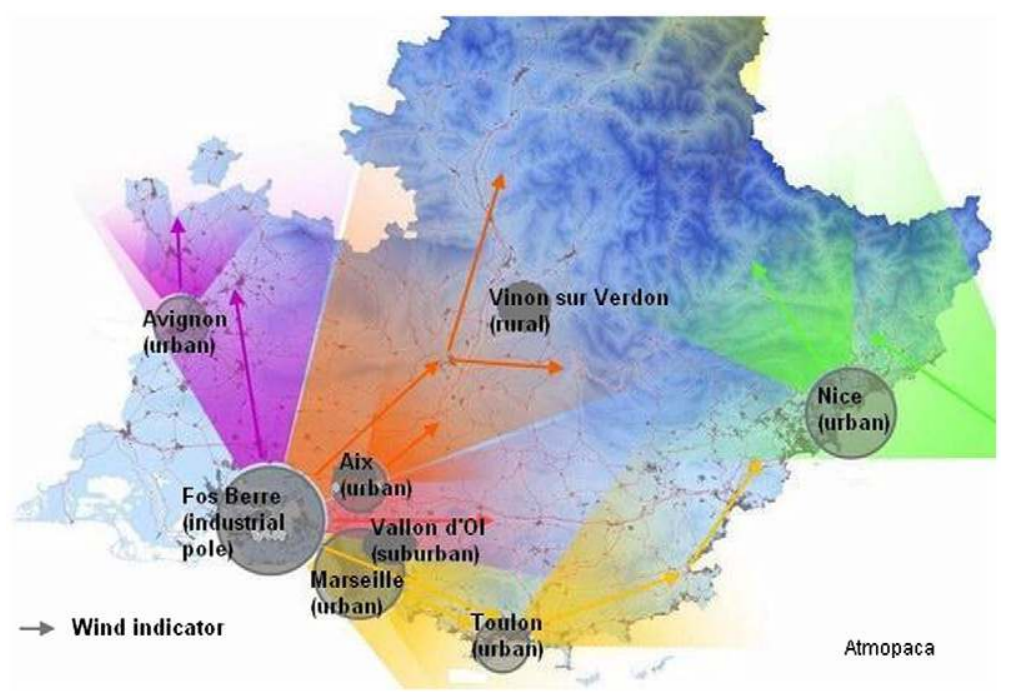

Fig. 1. Prevailing directions of polluted air masses associated with wind/breeze phenomenon. 
Table 1

Period of data availability (Airmaraix: air quality agency)

\begin{tabular}{lllll}
\hline $\begin{array}{l}\text { Site } \\
\text { (data's origin) }\end{array}$ & $\begin{array}{l}\text { Avignon } \\
\text { (Airmaraix) }\end{array}$ & $\begin{array}{l}\text { Marseille } \\
\text { (Airmaraix) }\end{array}$ & $\begin{array}{l}\text { Toulon } \\
\text { (Airmaraix) }\end{array}$ & $\begin{array}{l}\text { Vallon d'Ol } \\
\text { (ESCOMPTE) }\end{array}$ \\
\hline Study's period & June to September 2004/2005 & June to July 2001 & July to September 2005/2006 & June to July 2001 \\
\hline
\end{tabular}

(above 1.5) have been considered so that they should be formally associated with fine particulate air pollution.

To obtain larger scale information, we use also MODIS AOT retrievals. MODIS is a spectroradiometer taken on board of the TERRA and AQUA platforms. The MODIS operational algorithm derives aerosol optical thickness at $470 \mathrm{~nm}$ and $660 \mathrm{~nm}$ wavelengths at $10 \mathrm{~km}$ resolution. A cloud mask is used to determine cloud cover above the area of measurement. The MODIS cloud mask algorithm classifies pixels as either confident clear, probably clear, probably cloudy or cloudy. This pixel categorization is the result of tests applied to 20 of the 36 MODIS spectral bands to identify the presence of clouds (including cirrus) in the instrument field-of-view (King et al., 2003). The complete description of MODIS remote sensing of aerosol over land is described by Kaufman et al. (1997). In this study, we use standard daily mean AOT data (cloud free) at $470 \mathrm{~nm}$. Uncertainty above continents is given by $0.05+0.2 \times$ AOT (Kaufman et al., 1997).

\section{Results and discussion}

\subsection{Comparison between PM10 ground mass concentrations and AOT from PHOTONS Sun photometers}

We present here analyses of daily mean PHOTONS AOT and daily mean PM10 ground mass concentrations at five sites during summer time. We focus our study on that period as under stagnant anticyclonic conditions, warm and cloud free days, majority of particulate pollutants are located in the well-mixed boundary layer as shown by Mallet et al. (2003) over this region. Such aerosol vertical profiles have been observed also by Sheridan and Ogren (1999), who showed that the largest values of aerosol light-scattering and absorption were observed into the boundary layer over large polluted areas in the United States.

Table 2 gathers correlation coefficients $R$ between daily mean PM10 ground mass concentration and daily mean PHOTONS AOT for each site. In urban areas (see Table 2), PM10 are well-correlated with AOT as $R$ ranges from 0.68 to 0.79 . These correlations found in polluted urban areas are comparable to those reported by Chaudhry et al. (2007), who found correlation coefficient of 0.67 between daily mean PM10 mass concentrations and daily mean AERONET AOT in Xianghe (south east of Beijing). In parallel, Kusmierczyk-Michulec et al. (2007) showed a slightly weaker correlation $(R=0.59)$ between AOT and hourly PM10 at The Hague (The Netherlands) located at the North Sea coast region.

Good correlations are also found over the suburban site of Vallon d'Ol $(R=0.79)$ and at the rural site of Vinon sur Verdon $(R=0.70)$ during summer 2001. These sites are characterized by the presence of anthropogenic gaseous and particulate pollution coming from Marseille and the industrial sites of Fos Berre (Fig. 1). These aerosols are mainly composed of anthropogenic sulphates and carbonaceous components (primary and secondary origin) with high light extinction efficiencies (Mallet et al., 2003). Consequently, in spite of the distance from pollution sources, good correlations between AOT and ground PM10 concentrations in these suburban and rural sites are observed.

As examples, Figs. 2 and 3 show temporal comparisons of daily mean PM10 mass concentration and AERONET AOT for the urban stations of Avignon and Toulon during summer 2005 and Marseille during summer 2001 (respectively Fig. 2 (a), (b) and (c)), and for the suburban site of Vallon d'Ol and the rural site of Vinon sur Verdon during summer 2001 (respectively Fig. 3(a) and (b)).

For urban sites (Fig. 2(a), (b) and (c)), we can observe a mean background pollution of particles equal to $20 \mu \mathrm{g} / \mathrm{m}^{3}$ and a corresponding mean background AOT of 0.15 . Added to this background pollution and during specific period, a peak of daily mean PM10 mass concentration coupled with an increase of daily mean photometric AOT is observed (from June 1, to June 3, 2005 and from July 2 to July 4, 2005 at Avignon for example (Fig. 2(a))). On the contrary, for some days, as on September 4, 2005 in Avignon (Fig. 2(a)), an increase of photometric AOT (0.27 to 0.46 ) is not correlated with an increase of PM10 mass concentration $\left(35 \mu \mathrm{g} / \mathrm{m}^{3}\right.$ to $33 \mu \mathrm{g} / \mathrm{m}^{3}$ ). Numerous reasons could justify such disagreements between AOT and ground-based PM concentrations.

First, a possible non-homogeneity in the solar extinction over the vertical dimension could significantly spoil correlations between PM10 and AOT. Spatial vertical resolved information about aerosol distribution could help us to explain some unexpected relations between ground PM10 and AOT. LIDAR measurements would strengthen our methodology as it could measure aerosol extinctions as a function of altitude. This would provide vertical information of particulate pollution when combined with ground-based measurements. As an example, Engel-Cox et al. (2006) showed recently that the

Table 2

Coefficients of correlation $(R)$ between daily mean PM10 mass concentrations and PHOTONS AOT and number of averaged days for AOT and PM10 measurements $(n)$ for the five sites studied during summer time

\begin{tabular}{lllll}
\hline & $R$ & & $n$ & \\
\hline Toulon (urban) & Summer & Summer & Summer & Summer \\
& 2005 & 2006 & 2005 & 2006 \\
& 0.68 & 0.74 & 69 & 74 \\
Avignon (urban) & Summer & Summer & Summer & Summer \\
& 2004 & 2005 & 2004 & 2005 \\
& 0.73 & 0.79 & 89 & 95 \\
Marseille (urban) & Summer 2001 & Summer 2001 \\
& 0.69 & 19 & \\
The Vallon d'Ol & Summer 2001 & Summer 2001 \\
(suburban) & 0.79 & 25 & \\
Vinon sur Verdon & Summer 2001 & Summer 2001 \\
(rural) & 0.70 & 17 & \\
\hline
\end{tabular}




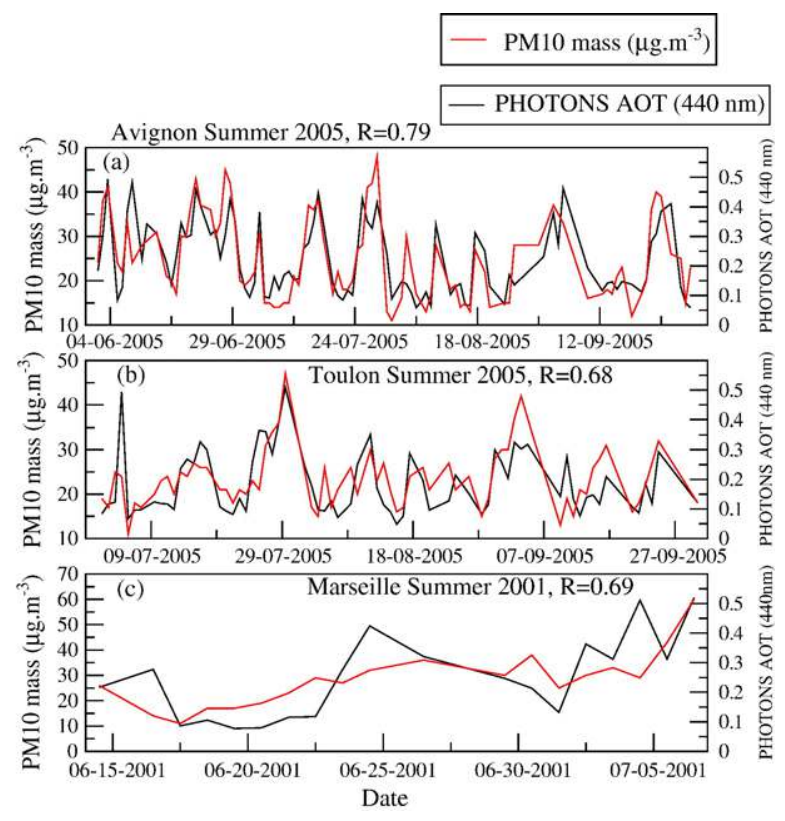

Fig. 2. Daily mean PM10 mass concentration and daily mean PHOTONS AOT for the urban stations of (a): Avignon and (b): Toulon during summer 2005 and (c): Marseille during summer 2001.

fraction of the aerosol optical depth that is within the planetary boundary layer (PBL) is better correlated with surface PM2.5 than the total AOT. Furthermore, the PBL height can have a negative impact on the link between AOT and PM concentration at the ground when fine particles emitted from the surface are diluted within the boundary layer as its height increases (Liu et al., 2005).

Associated with uncertainties in aerosol vertical profiles, the relative humidity $(\mathrm{RH})$ is also a key factor in the association AOT-PM. Hygroscopic components of PM aerosols like ammonium nitrate, ammonium sulphate and organic carbon can grow in size under high relative humidity ensuing an increase of their light extinction efficiencies (Malm et al., 2000). However, PM measurements correspond to dry particle mass, so a greater AOT value can correspond to the same PM concentration as RH increases. Further studies are needed to investigate the dependency of the water content to the chemical composition and relative humidity (Price et al., 2003) and quantify the influence of these factors on the correlation between PM10 and AOT over the PACA region.

Finally, it should be noted that the PM10 values observed at urban areas (a maximum daily mean value of $73 \mu \mathrm{g} / \mathrm{m}^{3}$ observed at Avignon during summer 2004) over the PACA region are less important than those observed in very strongly polluted cities like Hong Kong where severe pollution events can be observed (hourly PM10 >180 $\mu \mathrm{g} / \mathrm{m}^{3}$ ) associated with high AOT values (AOT >0.9) (Li et al., 2005).

Concerning Vallon d'Ol site, PM10 concentrations are similar than those observed in urban areas (Fig. 3(a)), which could denote a rapid formation of secondary aerosols that would compensate the dilution of primary particles emitted in sources areas (Cachier et al., 2005). Noting that on July 6 , 2001, we can observe a maximum in PM10 reaching $53 \mu \mathrm{g} / \mathrm{m}^{3}$ associated with an AOT equal to 0.79 . To further investigate this point, we computed a 72-h airmass back trajectory on July 6, 2001 on Vallon d'Ol using the NOAA HYSPLIT (Hybrid Single-Particle Lagrangian Integrated Trajectory) model with the FNL meteorological archive of NCEP Global Data Assimilation System model output. The arrival time of the airmass is 18 h UTC. High AOT levels observed at Vallon d'Ol (Fig. 3(a)) and also at Marseille (AOT=0.52) (Fig. 2(c)) and Vinon sur Verdon (AOT $=0.43$ ) (Fig. $3(\mathrm{~b})$ ) is due to the conjunction of two phenomena occurring that day.

At the surface, the south-easterly flow (sea breeze) is prominent and induces a meso-scale cycling circulation of pollutants. This sea breeze brings back inland aged pollutants (that were advected over the sea during the night by the reverse flow (land breeze)), which is added to new emissions of pollutants.

Aloft, meteorological conditions are characterized by a Cold Drop centered on the Gulf of Gascogne that drives a south-westerly flow on the region. Pollutants emitted on the Iberian Peninsula are advected over the west Mediterranean coast and induce a transborder additional pollution.

The meso-scale cycling circulation of pollutants and long range transport give evidence of a remarkably high level of air pollution along the atmospheric column and hence high level of AOT, over the PACA region on July 6, 2001.

At the rural background site of Vinon sur Verdon (Fig. 3(b)), we can observe that maximum values of PM10 are less important than those reported in urban or suburban sites over the PACA region. PM10 reaches $32 \mu \mathrm{g} / \mathrm{m}^{3}$ on June 25 , 2001 against PM10 reaching $73 \mu \mathrm{g} / \mathrm{m}^{3}$ on July 23, 2004 at the urban site of Avignon and $53 \mu \mathrm{g} / \mathrm{m}^{3}$ on July 6, 2001 at the suburban site of Vallon d'Ol. During their transport from pollution sources (Marseille and Fos Berre, cf Fig. 1), additional effects of aerosols mixing into cleaner air and dry deposition cause a continuous decrease of the PM10 concentrations.

It is noteworthy that Chu et al. (2003) observed more important daily PM10 values (daily PM10 $>50 \mu \mathrm{g} / \mathrm{m}^{3}$ ) at the rural background site of Ispra at the north of Milan in the Po Valley. That seems to indicate the larger regional influence of the Milan urban and industrial area compared to Marseille/ Fos Berre complex. However, even if PM10 concentrations are lower over Vinon than in rural and suburban areas, aerosol optical thickness seems still sensitive to aerosol loading variations far from pollution sources, with a correlation coefficient $R$ of 0.70 (Fig. 3(b)).

The main conclusion of this part is that we underline an important and striking result as a link clearly appears between PM10 ground mass concentrations and aerosol optical thickness whatever the distance from pollution sources over the PACA region.

\subsection{Mapping of PM10 surface concentrations by using the MODIS sensor}

\subsubsection{Empirical relationship development}

In order to develop an empirical relationship between ground PM10 and ground-to-space AOT, we use the complete data set presented above. We gather data from the five sites studied to strengthen the statistical approach and we tend to establish a linear relation (Fig. 4). This simple linear model links daily mean PM10 mass concentration from daily mean 

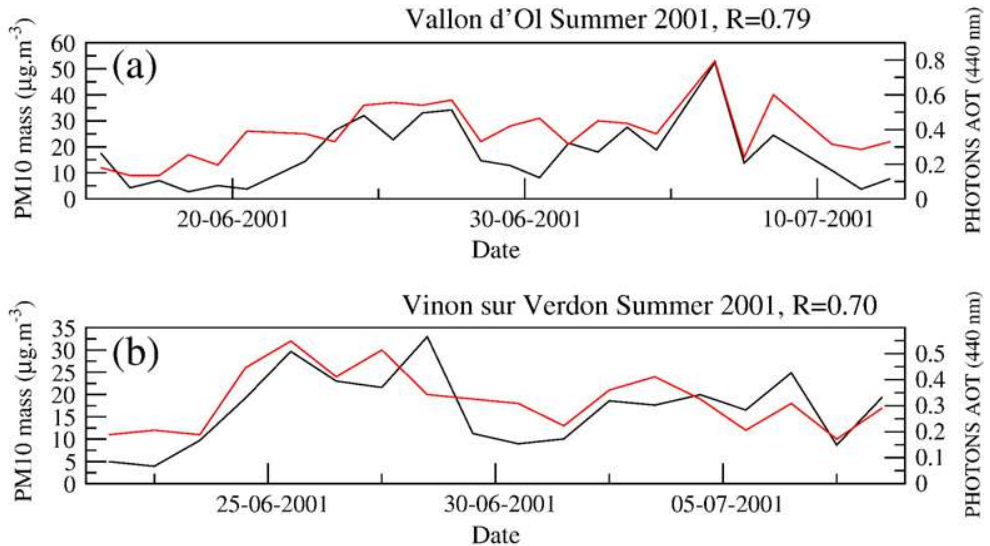

Fig. 3. Daily mean PM10 mass concentration and daily mean PHOTONS AOT for the suburban site of (a): Vallon d'Ol and the rural site of (b): Vinon sur Verdon during summer 2001.

AOT whatever the distance from pollution sources. The equation of the linear regression is:

$\mathrm{PM} 10=54 \times$ AOT +13.

The correlation coefficient is $R=0.69$ and the intercept is equal to 13 . This result has to be compared with the one found by Chu et al. (2003) between daily mean PM10 mass concentrations and PHOTONS AOT at Ispra (Italy) measured from August to October 2000. They obtained the following relation: PM10 $=55 \times A O T+8$, $(R=0.82)$, close to the one obtained in our study. Nevertheless, they found an intercept of 8 and an important coefficient of correlation $(R=0.82)$ that seems to indicate a stronger linear association between PM10 and AOT. This may be due to the fact that this comparison was made locally (Ispra) whereas our comparisons are made at a regional scale. At the present, it is very difficult to explain such biases and one reason could be the error generated by the vertical profiles of aerosols, not always located at the surface and used in our linear regression. This specific point should be clearly investigated in future studies. In the next section, we use the linear relation (1) between AOT and PM10 to evaluate daily mean PM10 mass concentration from the MODIS AOT product over the PACA region.

\subsubsection{Application of the linear model to MODIS AOT retrievals}

Before applying the linear relationship (1) to MODIS AOT, we have first compared the AOT measured from MODIS with those obtained from photometers. We recall here that uncertainties on MODIS AOT data are 0.05+0.2×AOT (Kaufman et al., 1997). They are mainly due to surface reflectance estimation and aerosol model (Remer et al., 2005). Concerning AERONET AOT, uncertainties are significantly lower $( \pm 0.01)$ (Holben et al., 1998). In order to perform rigorously comparisons between MODIS and AERONET AOT, we use data collocated in time and space. For each MODIS AOT data, we chose the closest AERONET's one within a time interval of $\pm 30 \mathrm{~min}$. Fig. 5 shows the validation of MODIS AOT retrievals by AOT data from
PHOTONS measurements over Toulon. This graph encompasses 150 points from June 01 to September 30, 2005 and 2006.

The small deviation of slope from unity (slope $=1.01$ ), the small intercept $(=0.02)$ and the coefficient of correlation ( $R=0.92$ ) of the linear regression indicate clearly the excellent agreement between MODIS sensor and PHOTONS Sun photometer, as shown previously by Chu et al. (2002) that made a global validation of MODIS AOT with AERONET measurements from Europe, eastern United States, East Asia, South America and southern Africa: $\mathrm{AOT}_{\text {MODIS }}=0.86 \times \mathrm{AOT}_{\text {AERONET }}+0.06, R=0.91$; and a regional validation in Western Europe: $\mathrm{AOT}_{\text {MODIS }}=$ $0.92 \times \mathrm{AOT}_{\mathrm{AERONET}}+0.04, R=0.92$. Thanks to the agreement between MODIS sensor and AERONET Sunphotometer, we use MODIS AOT retrievals to evaluate PM10 ground mass concentrations over the PACA region (Fig. 6).

Fig. 6 shows AOT at $470 \mathrm{~nm}$ from MODIS on June 29, 2006 at 11 h 05 UTC over PACA region. For black areas, MODIS retrieval algorithm did not perform because of the presence of

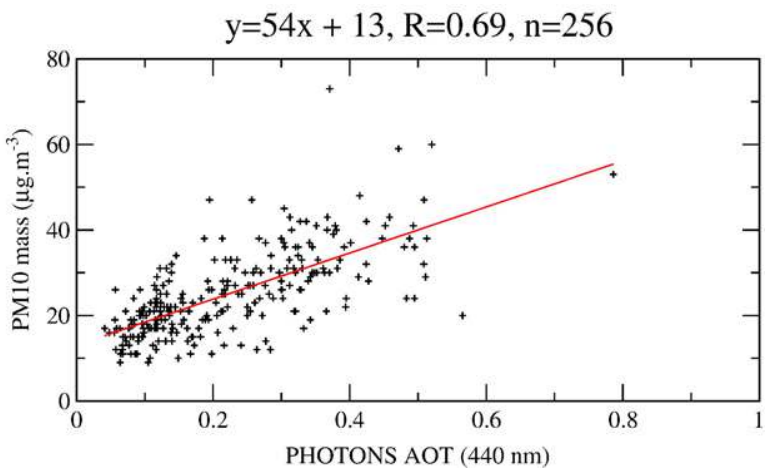

Fig. 4. Daily mean PM10 mass concentrations versus photometric AOT for the five sites studied during summer time. The equation of the linear regression is $\mathrm{PM} 10=54 \times \mathrm{AOT}+13, R$ (coefficient of correlation) $=0.69, n$ (regression points number $)=256$. 


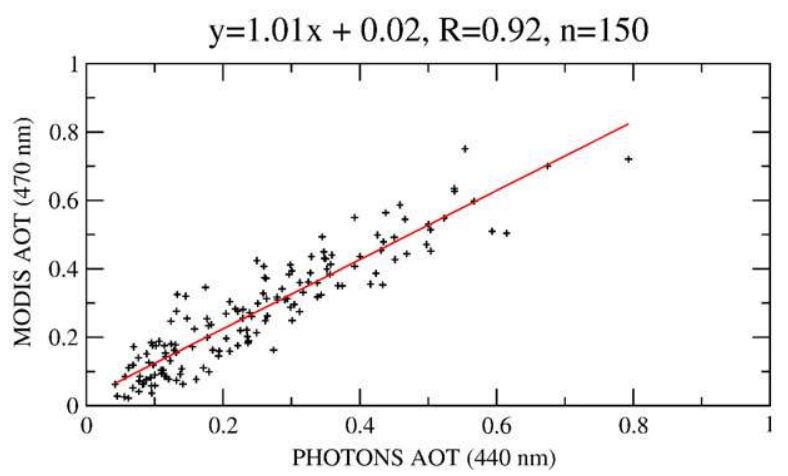

Fig. 5. MODIS AOT (470 nm) versus PHOTONS Sun photomoter AOT (440 nm) measured at Toulon. The equation of the linear regression is AOT $_{\text {MODIS }}=$ $1.01 \times$ AOT $_{\text {PHOTONS }}+0.02, R$ (coefficient of correlation) $=0.92, n$ (regression points number) $=150$.

dense cloud cover. On Fig. 6, we can see, globally, relatively high AOT values (around 0.5 and 0.6 ) above the densely populated and industrialized Mediterranean coast with a maximum of about 0.7 above the city of Nice. Lower AOT values (around 0.2 and 0.3 ) are present in less populated areas distant from the coast.

We use directly the equation (PM10=54×AOT +13 ) estimated from PHOTONS AOT and surface PM concentrations, with MODIS AOT values of the Fig. 6 . We also obtain the daily mean PM10 ${ }_{\text {estimated }}$ scale. For each site located on Fig. 6, we estimate a range of values of PM10 $10_{\text {estimated }}$. Validation is performed by using PM10 values measured by local air quality agencies

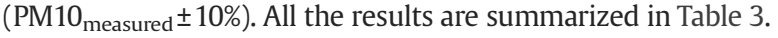

For the site of Marseille, the daily mean PM10 mass concentration is slightly underestimated on June 29, 2006 $\left(25 \mu \mathrm{g} / \mathrm{m}^{3}<\right.$ PM10 estimated $<35 \mu \mathrm{g} / \mathrm{m}^{3}$ and PM10 measured $=39 \pm$ $4 \mu \mathrm{g} / \mathrm{m}^{3}$ ) but the value remains in the same magnitude than the high estimated one, as for the Avignon site $\left(15 \mu \mathrm{g} / \mathrm{m}^{3}<\right.$ $\mathrm{PM}_{10}$ estimated $<25 \mu \mathrm{g} / \mathrm{m}^{3}$ and PM10 $10_{\text {measured }}=25 \pm 3 \mu \mathrm{g} / \mathrm{m}^{3}$ ). Over Toulon, our results indicate an important underestimation of

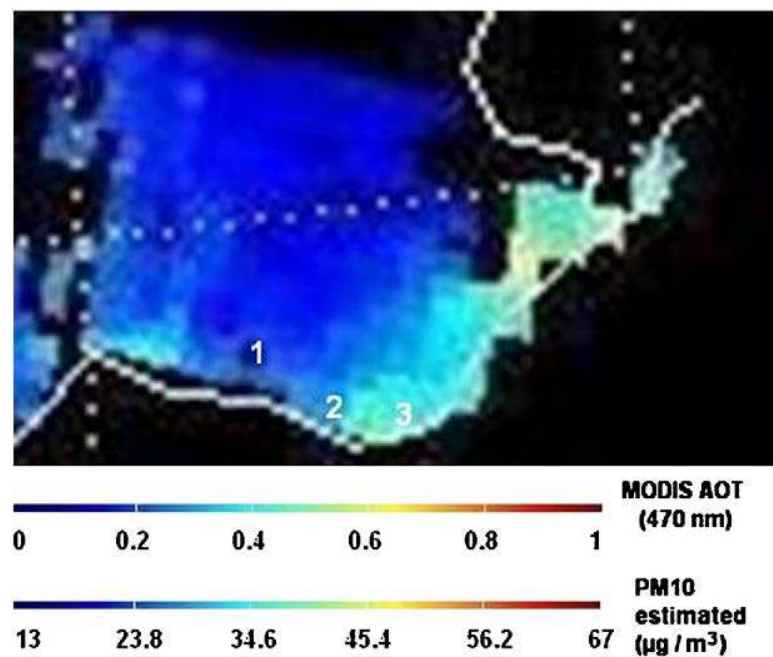

Fig. 6. Image of MODIS AOT at $470 \mathrm{~nm}$ during the 29th of June 2006 at $11 \mathrm{~h} 05$

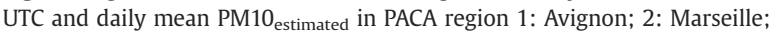
3: Toulon.
Table 3

PM10 ${ }_{\text {estimated }}$ calculated using the equation: $P M 10=54 \times A O T+13$ and PM10 measured supplied by local air quality agencies for June 29, 2006 for three urban cities located in PACA region

\begin{tabular}{|c|c|c|c|}
\hline & 1: Avignon & 2: Marseille & 3: Toulon \\
\hline PM10 ${ }_{\text {estimated }}\left(\mu \mathrm{g} / \mathrm{m}^{3}\right)$ & {$[15 ; 25]$} & {$[25 ; 35]$} & {$[30 ; 40]$} \\
\hline PM10 measured $\left(\mu \mathrm{g} / \mathrm{m}^{3}\right)$ & $25 \pm 3$ & $39 \pm 4$ & $58 \pm 6$ \\
\hline
\end{tabular}

PM10 concentration $\left(30 \mu \mathrm{g} / \mathrm{m}^{3}<\right.$ PM10 ${ }_{\text {estimated }}<40 \mu \mathrm{g} / \mathrm{m}^{3}$ and PM10 ${ }_{\text {measured }}=58 \pm 6 \mu \mathrm{g} / \mathrm{m}^{3}$ ) for that day.

\section{Conclusions and outlooks}

The aim of this work is to develop a methodology enabling to map PM10 ground mass concentrations by using satellite retrievals. To achieve this objective, first, we compare directly daily mean PM10 mass concentrations with daily mean AERONET/PHOTONS AOT. Our results show good correlations $(0.68 \leq R \leq 0.79)$ for five sites located in urban, peri-urban and rural zones over South-Eastern France. In a second time, we gather data of three types of sites in order to deduce an empirical relationship between daily mean PM10 mass concentrations and photometric AOT: PM10 =54 $\times$ AOT +13 . After validating AOT MODIS retrievals with PHOTONS measurements, we use our linear model to derive daily mean PM10 ground concentrations from a remote sensing image of AOT MODIS. Although the comparison of PM10 assessments with surface measurements over the PACA region confirms the potential of such method, uncertainties still remain as a link between AOT and PM10 is only pertinent when most of aerosols are confined in the boundary layer. The vertical profile of aerosol extinction from lidar clearly appears as crucial to further investigate the relationship between AOT and PM. In that sense, the determination of aerosol properties using both active (CALIOP: Cloud-Aerosol LIdar with Orthogonal Polarization) and passive (MODIS or POLDER) sensors on board the A-Train platform should further improve our methodology in satellite remote sensing of PM10 concentrations.

\section{Acknowledgements}

We would like to thank P. Goloub (Laboratoire d'Optique Atmosphérique), S. Despiau (Laboratoire d'études des Echanges Particulaires aux Interfaces) for the availability of data and G. Cailley for his help in imagery processing.

\section{References}

Agence Française de Sécurité Sanitaire Environnementale, 2004. . December Health Impact of Urban Atmospheric Pollution.

Albrecht, B.A., 1989. Aerosols, cloud microphysics and fractional cloudiness. Science 245, 1227-1230.

Allen, G., Sioutas, C., Koutrakis, P., Reiss, R., Lurmann, F.W., Roberts, P.T., 1997. Evaluation of the TEOM method for measurement of ambient particulate mass in urban areas. Journal of Air and Waste Management Association 47, 682-689.

Anderson, T.L., Charlson, R.J., Schwartz, S.E., Knutti, R., Boucher, O., Rodhe, H., Heintzenberg, J., 2003. Climate forcing by aerosols-a hazy picture. Science 300, 1103-1104.

Bessagnet, B., Hodzic, A., Blanchard, O., Lattuati, M., Le Bihan, O., Marfaing, H., Rouil, L., 2005. Origin of particulate matter pollution episodes in wintertime over the Paris Basin. Atmospheric Environment 39, 6159-6174.

Cachier, H., 1998. Carbonaceous combustion aerosols. In: Harrison, R.M., Van Grieken, R. (Eds.), Atmospheric Particles. Wiley, New York, pp. 295-348. 
Cachier, H., Aulagnier, F., Sarda, R., Gautier, F., Masclet, P., Besombes, J.-L. Marchand, N., Despiau, S., Croci, D., Mallet, M., Laj, P., Marinoni, A. Deveau, P.A., Roger, J.-C., Putaud, J.-P., Van Dingenen, R., Dell'Acqua, A., Viidanoja, J., Martins-Dos Santos, S., Liousse, C., Cousin, F., Rosset, R., Gardrat, E., Galy-Lacaux, C., 2005. Aerosol studies during the ESCOMPTE experiment: an overview. Atmospheric Research 74, 547-563.

Chaudhry, Z., Vanderlei Martins, J., Li, Z., Tsay, S.C., Chen, H., Wang, T., Wen, T., Li, C., Dickerson, R.R., 2007. In situ measurements of aerosol mass concentration and radiative properties in Xianghe, SE of Beijing. Journal of Geophysical Research 112, D23S90.

Chu, D.A., Kaufman, Y.J., Ichoku, C., Remer, L.A., Tanré, D., Holben, B.N., 2002 Validation of MODIS aerosol optical depth retrieval over land. Geophysical Research Letters 29, 1617-1620.

Chu, D.A., Kaufman, Y.J., Zibordi, G., Chern, J.D., Jietai, M., Chengcai, L., Holben, B.N., 2003. Global monitoring of air pollution over land from the Earth Observing System-Terra Moderate Resolution Imaging Spectroradiometer (MODIS). Journal of Geophysical Research 108, 4661-4678.

Cros, B., Durand, P., Cachier, H., Drobinski, Ph., Fréjafon, E., Kottmeier, C. Perros, P.E., Peuch, V.-H., Ponche, J.-L., Robin, D., Saïd, F., Toupance, G., Wortham, H., 2003. The ESCOMPTE program: an overview. Atmospheric Research 69, 241-279.

Drobinski, P., Saïd, F., Ancellet, G., Arteta, J., Augustin, P., Bastin, S., Brut, A., Caccia, J.L., Campistron, B., Cautenet, S., Colette, A., Cros, B., Corsmeier, U., Coll, I., Dabas, A., Delbarre, H., Dufour, A., Durand, P., Guénard, V., Hasel, M., Kalthoff, N., Kottmeier, C., Lasry, F., Lemonsu, A., Lohou, F., Masson, V., Menut, L., Moppert, C., Peuch, V.H., Puygrenier, V., Reitebuch, O., Vautard, R., 2006. Regional transport and dilution during high pollution episodes in southern France: summary of findings from the Field Experiment to Constraint Models of Atmospheric Pollution and Emissions Transport (ESCOMPTE). Journal of Geophysical Research 112, D13105.

Engel-Cox, J.A., Holloman, C.H., Coutant, B.W., Hoff, R.M., 2004. Qualitative and quantitative evaluation of MODIS satellite sensor data for regional and urban scale air quality. Atmospheric Environment 38, 2495-2509.

Engel-Cox, J.A., Hoff, R.M., Rogers, R., Dimmick, F., Rush, A.C., Szykman, J.J., AlSaadi, J., Chu, D.A., Zell, E.R., 2006. Integrating lidar and satellite optical depth with ambient monitoring for 3-D dimensional particulate characterisation. Atmospheric Environment 40, 8056-8067.

Goloub, P., 2004. Aerosol teledetection by photometry. ORE PHOTONS/ AERONET (ORA) presentation. Instrumentation and Experimentation workshop, 23-24 mars 2004. Paris, France.

Hodzic, A., Vautard, R., Bessagnet, B., Lattuati, M., Moreto, F., 2005. Long-term urban aerosol simulation versus routine particulate matter observations. Atmospheric Environment 39, 5851-5864.

Holben, B.N., Eck, T.F., Slutsker, I., Tanré, D., Buis, J.P., Setzer, A., Vermote, E. Reagan, J.A., Kaufman, Y.J., Nakajima, T., Lavenu, F., Jankoviak, I., Smirnov, A., 1998. AERONET-A Federated instrument network and data archive for aerosol characterization. Remote Sensing Environment 66, 1-16.

Kacenelenbogen, M., Léon, J.-F., Chiapello, I., Tanré, D., 2006. Characterisation of aerosol pollution events in France using ground-based and POLDER-2 satellite data. Atmospheric Chemistry and Physics 6, 4843-4849.

Kaufman, Y.J., Tanré, D., Remer, L., Vermote, E., Chu, A., Holben, B.N., 1997. Operational remote sensing of tropospheric aerosol over the land from EOS-MODIS. Journal of Geophysical Research 102, 17051-17068.
Kaufman, Y.J., Tanré, D., Boucher, O., 2002. A satellite view of aerosols in the climate System. Nature 419, 215-223.

King, M.D., Menzel, W.P., Kaufman, Y.J., Tanré, D., Gao, B.C., Platnick, S., Ackerman, S.A., Remer, L.A., Pincus, R., Hubanks, P.A., 2003. Cloud and aerosol properties, precipitable water, and profiles of temperature and humidity from MODIS. IEEE Transactions on Geoscience and Remote Sensing 41, 442-458.

Kumar, N., Chu, A., Foster, A., 2007. An empirical relationship between PM2.5 and aerosol optical depth in Delhi Metropolitan. Atmospheric Environment 41, 4492-4503.

Kusmierczyk-Michulec, J., de Leeuw, G., Moerman, M.M., 2007. Physical and optical aerosol properties at the Dutch North Sea coast. Atmospheric Chemistry and Physics Discussion 7, 1557-1594.

Li, C., Kai-Hon, A., Mao, J., Chu, D.A., 2005. Retrieval, validation and application of the 1-km aerosol optical depth from MODIS measurements over Hong Kong. IEEE Transaction on Geoscience and Remote Sensing 43, 2650-2658.

Liu, Y., Sarnat, J.A., Kilaru, V., Jacob, D.J., Koutrakis, P., 2005. Estimating ground-level PM2.5 in the Eastern United States using satellite remote sensing. Environmental Science and Technology 39, 3269-3278.

Mallet, M., Roger, J.-C., Despiau, S., Dubovik, O., Putaud, J.-P., 2003. Microphysical and optical properties of aerosol particles in urban zone during ESCOMPTE. Atmospheric Research 69, 73-97.

Malm, W.C., Day, D.E., Kreidenweis, S.M., 2000. Light scattering characteristics for aerosols as a function of relative humidity: part I: a comparison of measured scattering and aerosol concentrations using the theoretical models. Journal of the Air and Waste Management Association 50, 686-700.

Ors Paca, 2004. Health-Environment Regional Picture.

Price, M., Bulpitt, S., Meyer, M.B., 2003. A comparison of PM10 monitors at a Kerbside site in the northeast of England. Atmospheric Environment 37, 4425-4434.

Remer, L.A., Kaufman, Y.J., Tanré, D., Mattoo, S., Chu, D.A., Martins, J.V., Li, R.-R., Ichoku, C., Levy, R.C., Kleidman, R.G., Eck, T.F., Vermote, E., Holben, B.N., 2005. The MODIS aerosol algorithm, products and validation. Journal of the Atmospheric Sciences 62, 947-973.

Sheridan, P., Ogren, J., 1999. Observations of the vertical and regional variability of aerosol optical properties over central and eastern North America. Journal of Geophysical Research 104, 16793-16805.

Smirnov, A., Holben, B.N., Eck, T.F., Dubovik, O., Slutsker, I., 2000. Cloudscreening and quality control algorithms for the AERONET database. Remote Sensing of Environment 73, 337-349.

The Intergovernmental Panel on Climate Change. 4th Assessment Report 2007.

Twomey, S., 1974. Pollution and the planetary albedo. Atmospheric Environment 8, 1251-1256

Vachon, F, Royer, A., Aubé, M., Toubbé, B., O'Neill, N.T., Teillet, P.M., 2004. Remote sensing of aerosols over North American land surfaces from POLDER and MODIS measurements. Atmospheric Environment 38, 3501-3515.

Van Donkelaar, A., Martin, R.V., Park, R.J., 2006. Estimating ground-level PM2.5 using aerosol optical depth determined from satellite remote sensing. Journal of Geophysical Research 111, D21201. 